\title{
Españoles EN El Gulag: AnÁlisis DEL TEXTO TEATRAL "El mensaJE" DE JAime SAlOM
}

\author{
JESÚs GuZMÁN MORA
}

Title: Spaniards in the Gulag: Analysis of the Dramatic Text El mensaje, by Jaime Salom.

Abstract: El mensaje is a dramatic text by Jaime Salom premiered in I95s in the Arriaga Theater, in Bilbao. It is about the captivity of the Spaniards in the Gulag of the Soviet Union, a forgotten theme nowadays. The aim of our paper is to observe the experience of the Spaniards in the Gulag in El mensaje. For it, we analyze the dramatic text and then we study the references that Salom does about the Gulag to contextualize with the rest of the Spanish literary and historical books of the Gulag.

Key words: Jaime Salom. El mensaje. Theater in the Francoist Spain. Literature and Gulag. Spain and World War.

\section{INTRODUCCIÓN}

Dentro de la producción teatral de Jaime Salom (1925-2003) se encuentra El mensaje, obra que proponemos para su estudio debido a la presencia de un tema poco tratado en los estudios literarios académicos: los textos ficcionales y testimoniales que toman como base la experiencia de los españoles en el Gulag soviético. Para ello, estructuramos nuestro trabajo de la siguiente manera: veremos, en primer lugar, algunos aspectos en torno al análisis teatral de El mensaje. En segundo lugar, observaremos qué entendemos por literatura española del Gulag para comprender el contexto literario de la obra. Y, en tercer lugar, analizaremos los aspectos referentes al Gulag en la misma. Realizaremos este último apartado en torno a la bibliografía histórica y el corpus literario existente sobre el tema. Con ello intentamos cumplir nuestra hipótesis, por la cual consideramos que El mensaje es una obra apta para entrar dentro de aquellas que clasificamos como literatura española del Gulag.

2. El mensaje, de Jaime Salom: anÁlisis del texto teatral

Nuestro análisis del texto teatral se basa en varias cuestiones que, a pesar de su carácter descriptivo y no profundizar en cuestiones de relieve, nos darán datos suficientes para comprender mejor El mensaje, de Jaime Salom. Estas son: la presentación sinóptica de la obra, el lugar que ocupa 
dentro de la bibliografía del autor, la estructura interna, las coordenadas espacio-temporales y la representación y recepción de la misma.

Esta obra de teatro escrita por Jaime Salom sitúa en escena a Flora, quien vive en concubinato con Augusto, un músico de éxito. Su matrimonio es irrealizable porque ella está casada con Carlos, combatiente de la División Azul desaparecido en la Unión de Repúblicas Socialistas Soviéticas (URSS), unión llevada a cabo más por conveniencia que por amor. En torno al prisionero gira toda la acción aunque es el gran ausente al no aparecer en las tablas. La vida de la esposa se ve turbada por la llegada de Germán, un hombre que, durante los años previos a la Guerra Civil, había trabajado como subordinado del marido, al que había causado problemas. Este, conocido como el Asturias, sobrenombre que delata su posición política, le revela que ha coincidido con Carlos en el Gulag, donde aún sobrevive -afirmación falsa- como prisionero. Germán le confiesa que el motivo de su visita es la transmisión de un mensaje de amor y esperanza del reo para ella, una segunda mentira ya que es él el que ha regresado para confesar su amor platónico por Flora. Completan el reparto el Inspector Ruiz, quien sigue la pista del llegado por su militancia clandestina de izquierdas y Fernanda, sirvienta de la casa.

El mensaje, considerada por el autor como "mi auténtica primera obra" (Salom, 2005: 45), ha sido clasificada, junto a Verde esmeralda y Culpable, dentro de sus textos "amorosos-policiales", en los que aparecen "inquietudes [afectivo-morales]" combinadas "con estructuras propias del género policiaco" (Izquierdo Gómez, 1993: 23). Se ha apuntado que el uso de estas formas puede venir dado por la influencia del teatro de J. B. Priestly, cuyas obras Dangerous Corner (1932), I Have Been Here Before (1937) y An Inspector Calls (1945) fueron estrenadas en España en la década de 1950. Especialmente notable sería el influjo de la última de ellas, representada en la época en dos versiones diferentes: La herida del tiempo, de Luis Escobar, y Llama un inspector, de Cayetano Luca de Tena (Zatlin-Boring, 1982: 42-44). En ella, se hace notar "la preocupación por la culpa y la redención, todavía envueltas en un simbolismo demasiado melodramático que depuró con 
posterioridad" (Conde Guerri, 2005: 2 I). De acuerdo con Paul Preston, en El mensaje, como "en el conjunto de sus obras [Salom] ha sabido mezclar un gran interés por la historia con una percepción agudísima de la psicología humana” (2005: i4). A pesar de que Jaime Salom ya había escrito otras obras, puede ser considerada la aquí estudiada como el punto de partida de su producción teatral - fue la primera de todas que se representó-, que combinó con su trabajo de oftalmólogo y que llevó hasta el mismo año de su fallecimiento. Es un "texto aún titubeante, lleno de cargas ideológicas y próximas a lo melodramático y con un encorsetamiento retórico, «literaturizado» en los diálogos, que estaban muy lejos todavía de la habilidad y frescura que luego fue adquiriendo" (Torres Nebrera, 2004: I 30).

La obra está escrita en un contexto histórico concreto: en 1953 el régimen había firmado los "Pactos de Madrid" con los Estados Unidos de América y el Concordato con la Iglesia Católica. En ese mismo año había fallecido Iósif Stalin y, un año después, regresaron los divisionarios presos del Gulag. Tras el final de la Guerra de Corea -y desde la misma-, la Guerra Fría alcanzó altos niveles de tensión hasta llegar a la crisis de los misiles de Cuba. El antisovietismo del franquismo debía mostrarse por cualquier vía y una de ellas, más allá de la mayor o menor incidencia que pudiera tener, se materializaba a través de la literatura. Aparecieron nuevos textos de antiguos combatientes de la División Azul o traducciones de testimonios que daban fe de nefastas experiencias en la URSS. Incluso se utilizaban clásicos como La Russie en I839 (1843) del marqués de Custine para ofrecer una imagen negativa de la nación en la época contemporánea. ${ }^{\mathrm{I}}$

'En esta época destacan, en la literatura divisionaria, División 250 (Tomás Salvador, I954) y Tudá (Allá) (Luis Romero, I957). En el caso de los testimonios encontramos, entre otros, Moscú era mi parroquia (1958) del reverendo Georges Bissonette. Este hombre fue procesado y expulsado del país, donde ejerció como responsable espiritual de la comunidad norteamericana en la URSS entre 1953 y i955. El ejemplo del marqués de Custine es significativo: su libro, en el que presenta una negativa imagen de Nicolás I y su mandato, fue reeditado en I 953 con el título, de libre traducción, Rusia, ayer como hoy. En el prólogo añadido a la nueva edición se dice que muchos pasajes podrían aparecer "sin retoques como artículo editorial de un diario publicado en la mañana de hoy" (Camps, i 953: 8). Incluso uno de los capítulos se titula, en claro anacronismo intencionado, "Anticipación de i94I" (Marqués de Custine, i953: I 89). 
El texto se estructura en tres actos: el primero nos presenta a Flora, preocupada porque se sintió observada unos días atrás por un hombre del que huyó, lo que le transmite al Inspector Ruiz. A continuación entra en escena Germán, que ha regresado para conversar con ella, quien decide confesar a Augusto quién era este hombre. En el segundo Flora y Augusto discuten porque Flora quiere encubrir a Germán frente al Inspector Ruiz, quien descubre que Flora no está casada con Augusto, sino con Carlos. Germán, cuando regresa a escena, intenta besar a Flora, que se resiste. El Inspector Ruiz informa a Flora que Carlos no regresará del Gulag porque ha fallecido allí. Y en el tercero, Germán promete entregarse a la policía si le dan la oportunidad de hablar unos minutos a solas con Flora, a quien confiesa su enamoramiento. La obra finaliza con la redención de Flora ante la memoria de Carlos. Toda la obra se desarrolla en el gabinete de la casa de Flora y Augusto a lo largo de varios días "en la primavera de I954, en España” (Salom, ı963: го). El primer acto comienza a "las siete de la tarde de un jueves a fines de marzo" (i 963: I I), el segundo a "media mañana" (i 963: 30) del día siguiente y el tercero unos "pocos días después” (1 963: 49). Todos estos días son anteriores al regreso de los españoles en el barco Semíramis el día 2 de abril de i 954 en el Puerto de Barcelona, ya que en la obra leen la noticia en el periódico que indica que " 286 cautivos van a ser repatriados»" ( 1 963: 4I-42), pero en ningún momento posterior se anuncia la llegada o los personajes asisten a ella.

Para finalizar este apartado, cabe reseñar brevemente cuál fue la recepción de la obra en el momento de su puesta en función. De su estreno en Bilbao se dijo en La Vanguardia Española que obtuvo un "gran éxito de crítica y público” (1955: 22). En el mismo periódico se reseñó la vuelta a las tablas, cuatro años después, en la capital catalana. Para Martínez Tomás fue una comedia “ingeniosa”, "trazada con auténtica maña”, llena de "recursos de ágil fertilidad imaginativa” y que desarrolló "un tema a la vez sutil y complicado" (1959: 90). José Fernández Aguirre, en la edición de la ciudad condal de La Hoja del Lunes, destacó de ella el ser "una obra muy digna, muy hermosa y escrita honradamente", que "plantea un problema actual y 
doloroso; es una consecuencia del mundo partido que llega también a separar a las almas", un problema que "Jaime Salom resuelve muy teatralmente [...] y nos obliga a rendirle nuestro aplauso" (I959: 2I). Y, según Martí Farreras, en Destino, trató un "tema peligroso en todas las acepciones del vocablo, [que] ha sido utilizado por Jaime Salom, aprovechando lo esencial, lo humanamente importante del mismo y rehuyendo a la vez los toboganes melodramáticos y discursivos de tan manifiesta tentación" (1959: 45). Además, el aparato de censura no puso ninguna objeción a su publicación en libro al igual que no había mostrado ningún inconveniente años atrás con el estreno de la obra (Archivo General de la Administración, caja 2 I/ I 4358 , expediente $\left.\mathrm{n}^{\circ} 330-63\right)$.

\section{El Gulag como tema en "El mensaje"}

Para nosotros, el tema del Gulag tiene especial importancia dentro de El mensaje. En la actualidad, y gracias a la frágil y en ocasiones cainita memoria patria, los españoles que penaron en el Gulag han sido olvidados del mismo modo que ha ocurrido con los prisioneros de los campos de exterminio del nacionalsocialismo (Sánchez Zapatero, 20 Io: 34 ). Antes de observar la presencia de este en la obra, nos proponemos realizar unas breves anotaciones sobre el Gulag y repasar el corpus de lo que podemos considerar como la literatura española del Gulag.

\section{3.r. El Gulag, destino de los españoles}

El Gulag fue un sistema de destrucción humana que llevó a la anulación sistemática del individuo mediante una forma de esclavitud contemporánea. Era el último destino del sistema carcelario ruso, aquello que "los prisioneros solían llamar la «trituradora de carne»" (Applebaum, 20I4: 20). Es cierto que, salvo trágicas excepciones como Cholnogory (Ciechanowski, 2005: 6I), la metodología bolchevique no contempló el exterminio a la manera del Lager. Pero esto no hizo más "agradables los campos rusos", en los que "el hambre infligido voluntariamente como castigo por un trabajo que se consideraba insuficiente, las enfermedades no cuidadas y propagadas por la mugre o el frío de las tundras siberianas mataban con igual crueldad que el gas, aunque más lentamente" (Todorov, 2002: I27). Aunque no pro- 
fundizaremos en la cuestión para no alejarnos de nuestro objetivo, creemos necesario recuperar las palabras de Iordache para referirnos a este sistema represivo:

El Gulag fue un tamiz político-social que proveía la mano de obra del "enemigo del pueblo", que se debía reeducar a través del sistema masivo de trabajo forzado. Por otro lado, el sistema concentracionario soviético cumplía la misión de purificar la sociedad de los "elementos indeseables" que contaminaban el camino hacia el sueño utópico, una sociedad socialista perfecta (2014: I43).

Aunque la población soviética fue la principal víctima del Gulag, la maquina del terror no realizó excepciones con los ciudadanos extranjeros. ${ }^{2}$ Los españoles estuvieron entre ellos: Xavier Moreno Juliá (2005: 322) ha recordado que el gobierno franquista fijó el número de presos divisionarios en 372 , de los que i s habrían muerto durante el cautiverio. El viceministro de Asuntos Exteriores soviético Andrei Grominko la redujo, en la década de 1950 , a 289 supervivientes, número menor al que han desvelado recientemente los archivos rusos, que la han elevado a 452, de los cuales 70 fallecieron. En todo caso, este autor fija la cantidad en más de 400 e incluso se atreve a afirmar que pudieron ser más de medio millar, cifra que parece más cercana a la realidad. ${ }^{3}$ Secundino Serrano (20I I) y Luiza Iordache (20I4) han relatado la experiencia de los republicanos que pasaron por el Gulag. Las víctimas provenían de diferentes sectores: marinos y aviadores al servicio de la II República que se encontraban en el país de los soviets cuando finalizó la Guerra Civil, los niños de la guerra, varios de los desertores de la División Azul -utilizados durante la II Guerra Mundial y encarcelados tras

${ }^{2}$ Para su trabajo, Meinhard Stark (1996: 172) entrevistó a dieciséis prisioneras alemanas que desde finales de la década de I920 e inicios de I 930 se habían trasladado a la URSS como esposas de ciudadanos soviéticos, trabajadoras de empresas alemanas o emigrantes. Los testimonios de los presos Melchior Wankowicz y Józef Czapski, considerados como los primeros de relevancia en el ámbito polaco, aparecieron en el año I 944 (Jaworska, 20 I4: 56-59). Luiza Iordache y Casilda Güell (2013: 256-257) han citado varios casos acerca de la bibliografía francesa e italiana en torno al Gulag.

${ }^{3}$ Vid. el reciente estudio de Torres (2018), cercano a las mil páginas, para observar con detalle la trayectoria de los divisionarios en el Gulag. 
el final de esta- y los protagonistas del "episodio berlinés". ${ }^{4}$ El grupo de los españoles presos del Gulag, como puede verse en esta rápida enumeración, fue el más heterogéneo:

Una de las características de los cautivos españoles fue su variedad. Ninguna otra nacionalidad aporta tipologías tan distintas de prisioneros. Esto se debe a que los prisioneros españoles en acción de guerra se encontraron como compañeros de cautiverio a personas que difícilmente cabía imaginar que hubieran tenido ese destino (2007: 372).

Este hecho dejó una huella entre los españoles que sobrevivieron a la experiencia, cuestión que fue aprovechada por el franquismo para la oportuna publicación de varios relatos sobre ella. En otro trabajo (Guzmán Mora, 2016: I04-I07) hemos clasificado la literatura no ficcional española del Gulag hasta 1975 en razón de sus límites temporales. Consideramos que existen tres momentos claramente diferenciados: entre 1947 y 1954 aparecieron lo que denominamos "publicaciones previas" y que están dedicadas no a los divisionarios sino a los republicanos exiliados presos, a quienes se presenta como equivocados en su ideal. Este grupo de textos está compuesto por dos libros que vieron la luz en España y otros dos que lo hicieron en Hispanoamérica. Los que aquí aparecieron son Españoles en Rusia (1947), del diplomático Rafael Miralles, que había apoyado durante la Guerra Civil a la II República, hecho que no le impidió denunciar la situación de los españoles en la URSS y el panfleto Españoles esclavos en Rusia (1952), de Eduardo Comín Colomer en la colección "Temas españoles". Y, al otro lado del océano, se pudo leer en México el primer testimonio de un español liberado del Gulag, En los dominios del Kremlin ( 8 años y medio en Rusia) (1950), del piloto republicano José Antonio Rico. A este título hay que sumar En busca de la verdad soviética: Por qué huyen en baúles los asilados españoles en la URSS (1951), del peronista Pedro Conde Magdaleno, un título en el que el

${ }^{4}$ Tras la caída de la capital de Alemania, un grupo de españoles refugiados en Francia y llevados a la fuerza a trabajar al Tercer Reich ocuparon la embajada franquista. Allí, tras unas semanas en las que no fueron molestados por los soviéticos, estos entraron en el edificio y se llevaron a 38 de ellos en dirección al Gulag, donde permanecieron hasta i 948 (Iordache, 2014: 193-200). 
tema central no es el Gulag pero en el que se narra la ayuda que prestó este diplomático a dos españoles que querían huir del país, misión que, como ha señalado Serrano (20 I I: I 53-I 57), resultó fallida.

El segundo grupo, que acoge los años comprendidos entre i954 y I960, es el que calificamos como "los años del auge propagandístico”. Entre ellos predominaron las memorias de los antiguos miembros de la División Azul "publicitados por el aparato cultural de la dictadura franquista en su afán de demonizar el sistema comunista” (Sánchez Zapatero, 20 Io: 8I). El listado de estos textos está compuesto por Yo, muerto en Rusia (Memorias del alférez Ocañas) (Moisés Puente, I954), En el abismo rojo: memorias de un español, once años prisionero en la U.R.S.S. (Ramón P. Eizaguirre, 1955), Embajador en el infierno: memorias del capitán Palacios. Once años de cautiverio en Rusia (Torcuato Luca de Tena, 1955), Enterrados en Rusia (Eusebio Calavia Bellosino y Francisco Álvarez Cosmen, 1956), De Leningrado a Odesa (César García Sánchez y Gerardo Oroquieta Arbiol, 1958) y Españoles en la U.R.S.S. (Juan Negro Castro, 1959). A estos libros memorísticos hay que añadir los escritos por los republicanos. El primero de estos ejemplos no es exactamente un libro de memorias, ya que Quince años en Rusia (1955) relata las "memorias del internado Fulgencio García Buendía distorsionadas" (Iordache, 20 I 5: I08). Junto a este texto aparecieron Rusia al desnudo: revelaciones del Comisario Comandante Español Rafael Pelayo de Hungría. Comandante del Ejército Ruso (Rafael Pelayo de Hungría, 1956) y Un piloto español en la U.R.S.S. (Juan Blasco, 1960). ${ }^{5}$

Para el bloque final, que recorre los últimos tres lustros del franquismo, no podemos mencionar ni un solo libro sobre el Gulag, lo que nos lleva a hablar de un "tiempo de silencio". Esta es una tendencia similar a la que vivió la propia literatura divisionaria que dio pie, con el regreso de los pri-

5Después de i975 han aparecido nuevos testimonios de españoles presos en el Gulag. Entre los divisionarios destacan 4.045 días cautivo en Rusia, 1943-1954. Memorias (Joaquín Poquet Guardiola, 1987) y Esclavos de Stalin: el combate final de la División Azul (Ángel Salamanca, 2002). Entre los republicanos ha aparecido el testimonio Invitado de honor (Miguel Velasco Pérez, i 995). 
sioneros, a una segunda oleada de publicaciones. ${ }^{6}$ Dicho mutismo propició que, en el ámbito de las letras de la División Azul, el "público [disfrutara] sólo obras de tono menor y reediciones de otras anteriores” (Ibáñez Hernández, I996: 86) y, directamente, de ninguna obra más en el ámbito del Gulag.

Más allá de esta división y, sobre todo, para extender nuestras investigaciones más allá de lo remarcado en el anterior estudio citado, queremos señalar la existencia de varios ejemplos en la ficción que han tomado al Gulag como tema principal o tangencial para la construcción de sus tramas. Durante la dictadura, aparecieron las novelas El desconocido (Carmen Kurtz, 1956) y La muerte está en el camino (José Luis Martín Vigil, I956). Esta última narra el regreso de Jorge, un español que había acudido a la URSS con la División Azul pero que, mientras esta se encontraba en la retaguardia, se había integrado en la División i 29 de la Webrmacht para tomar experiencia. Capturado con sus camaradas alemanes, es internado en un campo, del que consigue huir - por lo tanto, no regresa en el Semíramis- y llegar hasta España. Aquí debe afrontar una realidad desalentadora: su mujer ha fallecido y le ha dejado a su cargo a un hijo por el que no siente aprecio y al que, en realidad, adoptó su esposa. El vástago es fruto de la relación de su hermano menor con una mujer en sus tiempos de estudiante. Aunque este texto es un buen ejemplo literario sobre cómo tratar los efectos que causó el Gulag entre los presos y sus familiares - tema que, como veremos más abajo, está muy presente en El mensaje-, nosotros creemos que El desconocido es, de todo el corpus aquí recogido, la narración más próxima a la obra de Salom.

\footnotetext{
${ }^{6}$ En esta época destacan División 250 (Tomás Salvador, i 954) y Tudá (Allá) (Luis Romero, 1957), dos de los textos que marcan un cambio de paradigma en el discurso divisionario. Estamos de acuerdo con Sánchez Zapatero cuando ha descrito a la primera como "un fresco coral y poliédrico de los soldados españoles que participaron en el sitio de Leningrado" en que su autor "huye tanto del tono heroico como de la sublimación idealizadora" (20 I4: 8). Nuestra visión también está en sintonía con Rodríguez Puértolas cuando del segundo resalta su "estilo mucho más elaborado y digno que el de otros camaradas suyos, y una tónica ideológica también notoriamente distinta” (2008: 7 I 5).
} 
Carmen Kurtz es, a día de hoy, una escritora situada al margen del canon. ${ }^{7}$ En El desconocido recoge la historia de Dominica y Antonio. Ella recibe al marido al que creía muerto con la División Española de Voluntarios y él aparece como un fantasma del pasado incapaz de adaptarse a la nueva realidad tras su paso por el Gulag. Kurtz ofrece un interesante punto de vista al situar a la mujer en el centro del relato. En vez de cumplir el hombre con el arquetipo del héroe que ha derrotado al comunismo, observamos en esta novela, a través de una excelente introspección psicológica en los personajes, las sensaciones de Dominica ante Antonio, al que ve como a un extraño y que "sigue siendo un «desconocido» al final de la obra" (Bertrand de Muñoz, 200I: 136). Publicada con la misma oportunidad que El mensaje y el resto del corpus resaltado hasta al menos i960, consiguió el Premio Planeta en I 956.

Recientemente, el tema del Gulag ha sido retomado en la novela $M e$ hallará la muerte (Juan Manuel de Prada, 20 2 ). ${ }^{8}$ En ella, su autor narra la historia de Antonio Expósito, un estafador que, durante la postguerra, se alista en la División Azul para eludir una detención por asesinar a un hombre en el parque del Retiro. Al ser capturado en la URSS, el protagonista vive en primera persona el horror del Gulag. Allí toma la identidad de Gabi, un compañero que no consigue sobrevivir y con la que regresa a España en el Semíramis. Nosotros creemos que Juan Manuel de Prada utiliza como

${ }^{7}$ Recordada principalmente como autora de novelas infantiles — serie del niño Óscar y la oca Kina-, en su narrativa para adultos - vid., entre otros, Duermen bajo las aguas (1955), La vieja ley (1956), Detrás de la piedra (1 958), Las algas (1 966), Entre dos oscuridades (1969) o Cándidas palomas (1975)- criticó, dentro de los límites del momento, "los convencionalismos sociales, religiosos, sexuales, que lastran y coartan la libertad de las mujeres" y mostró "su osadía en temas como el divorcio, el aborto, el suicidio, en la denuncia de las profundas carencias que padecen - sostenidas y alimentadas socialmente-, en la falta de libertad, de independencia, de formación, que anulan sus perspectivas futuras” (Montejo Gurruchaga, 2006: 408).

${ }^{8}$ Aunque sea de manera breve, no queremos dejar de lado el caso de la española Lina Prokófiev (Carolina Codina Nemýsskaya), primera esposa del compositor Serguéi Prokófiev. Entre 1948 y 1956 estuvo recluida en el Gulag acusada de espionaje. Su caso ha sido estudiado en Lina Prokófiev: una española en el Gulag (Valentina Chemberdjí, 2009) y novelado en Una pasión rusa (Reyes Monforte, 2015). 
hipotextos (Genette, 1989: i9 y ss.) varios momentos de las obras de Torcuato Luca de Tena, Moisés Puente y José Luis Martín Vigil. Especialmente, repite este proceso con la escrita por Carmen Kurtz para construir la relación entre Antonio y Amparo, la novia del camarada desaparecido y que toma a Antonio como si fuera Gabi.

\subsection{El Gulag en "El mensaje"}

Somos conscientes de que el tema principal de El mensaje es la redención de la esposa a través de la muerte del marido. Pero toda la acción se sucede gracias a que Carlos se marchó con la División Azul y cayó preso de los soviéticos. Los aspectos referentes al Gulag nos permiten mostrar cómo reflejó Salom esta cuestión en la obra. Para su análisis, nos servimos de parte del corpus literario y de la bibliografía historiográfica arriba estudiados. Nosotros consideramos que la representación del Gulag se establece en varios subtemas: a través de la experiencia relatada por Germán respecto a su relación con Carlos en el Gulag, la ausencia de Carlos y cómo influye este aspecto en la vida de Flora y la vivencia individual de Carlos en el Gulag.

Carlos y Germán habían sido rivales antes de la guerra y, aunque no existen referencias ideológicas respecto a Carlos, sí podemos situarlos, sino como enemigos políticos, al menos en dos posiciones enfrentadas. Carlos, como miembro de la División Azul, representaría al convencido anticomunista, mientras que Germán es un comunista disidente con la línea del partido. Como ha dicho Iordache, "las historia de las “«dos Españas» [...] volvieron a encontrarse, esta vez en tierras lejanas, una con los prisioneros de la División Azul y otra con los republicanos internados, presos políticos, desterrados y delincuentes comunes" (2014: I 47). Allí Germán, que miente a Flora con este testimonio puesto que la relación entre ambos en la URSS había sido diferente, y Carlos habrían abandonado todas las diferencias del pasado al ser: "Compañeros de cautiverio... Coincidimos en el mismo barracón de presos políticos. Él fue un voluntario y yo un disidente de la línea del partido...", lo que bastaba para la reconciliación ya que hablaban "la misma lengua y amábamos la misma patria... Era suficiente” (1963: 20). La reconciliación entre españoles fue narrada por los divisionarios como un ac- 
to de perdón hacia los republicanos, quienes habrían descubierto su "error" - apoyar al comunismo soviético- en primera persona. A la disculpa se une la integración del exiliado en el ideario del vencedor a todos los niveles, entre los que destaca el religioso, ya que allí Carlos había enseñado a Germán "muchas cosas que no sabíamos o que ya habíamos olvidado", como "rezar" (1 963: 2 I). ${ }^{9}$ El capitán Teodoro Palacios Cueto, a través del relato de Torcuato Luca de Tena, muestra que el abrazo entre españoles no fue de igual a igual, sino de los vencedores de la guerra a los equivocados republicanos:

En el corazón de Rusia las dos Españas borraron sus diferencias. Allí se abrazaron para siempre. La una comprobó cuanto de Rusia sabía. La otra aprendió cuanto de Rusia ignoraba. Se fusionaron en un abrazo de sangre y sacrificio y, codo con codo, lucharon juntas, sufrieron procesos, soportaron condenas. ¡En los campos de concentración de Rusia terminó para nosotros la guerra civil! (Luca de Tena, I 993: 203).

Flora cree a Germán y así se lo hace saber al Inspector Ruiz cuando le dice que el Asturias se convirtió en el Gulag en un "amigo [de Carlos], sí, porque las viejas rivalidades y los viejos odios desaparecieron cuando se encontraron de nuevo... y pronto fueron entrañables compañeros, hermanos" (1 963: 45). Germán tuvo en el Gulag un comportamiento con Carlos totalmente opuesto al narrado por él, lo que confiesa al final de la obra. Carlos le hablaba "como a los demás, aun sabiendo que no iba a tener respuesta" (1963: 6I-62), lo que nos lleva a observar la otra cara de las relaciones entre los españoles en aquel lugar. El relato que nos ha legado esta literatura está dominado por la perspectiva de los divisionarios, que dibujaron a aquellos españoles que no tuvieron un buen comportamiento con ellos de manera

${ }^{9}$ En la novela breve Dios es corazón, del traductor de la Editorial Aguilar Amando Lázaro Ros, de temática religiosa, sucede un caso que se asemeja al aquí narrado. Uno de los personajes, un republicano español que lucha en la Resistencia y que va a ser ajusticiado, afirma que no es capaz de creer: "No lo veo a su Dios, padre; de verdad que no lo veo. Hace tiempo que lo despinté y que dibujé en su lugar un simple interrogante «?»" (I952: 62). Pero, en los momentos previos a su ejecución, inicia el rezo del Padrenuestro: "Creo en Dios Padre Todopoderoso, Creador del cielo y de la tierra... Luis Girón Menéndez [el personaje republicano] silba, muy quedo, la melodía de un himno que es una profesión de su fe" (I952: 79). 
negativa. Los casos recogidos no son los que afectan directamente a Germán, ya que él era un disidente político y no un carcelero afín a la línea marcada desde el poder soviético. Los antiguos combatientes de la División Azul, al igual que habían aceptado a los republicanos presos, llegaron a odiar a los compatriotas que actuaron como verdugos. Dos nombres fueron vilipendiados por ellos: el exiliado Felipe Pulgar, "convertido en la bestia negra de los españoles en el Gulag” y el desertor César Ástor, a quien se dedicaron "todos los tópicos de la maldad según los cánones franquistas" (Serrano, 20I I: 49 y 72). Este último, que sí reconoció el buen trato que los soldados falangistas dispensaron a la población rusa (Arasa, 2005: 330), fue definido como "un escuálido, con el rostro entre amarillo y verdoso, desdentado, con nariz de judío y una rizada cabellera, [al que] su voz atiplada y sus ademanes afeminados, le mostraban como un auténtico invertido" (Oroquieta Arbiol y García Sánchez, I958: 326). El Inspector Ruiz, parte del aparato estatal, resalta la actitud de Germán en el Gulag y que, con cierta distancia, puede conectarse con el recuerdo de estos dos hombres:

Es un ser de hierro. Podía tenderle una trampa y luego delatarle, y no lo hizo, eso es verdad... quizá por eso, por ser de hierro, orgulloso e imposible. Pero durante diez años... iy cuidado que son largos diez años de cautiverio!, el Asturias no le dirigió una sola vez la palabra. Otro hombre, de menos temple que su marido, hubiese enloquecido o le hubiese matado [...]. Pero aún hay más. Cuando existió una posibilidad de fuga, el Asturias usurpó el puesto que debía ocupar su marido y Carlos siguió allá mientras él lograba traspasar la frontera (1963: 46).

La experiencia de los divisionarios y su cautiverio es una historia en la que los hombres ocupan el papel central. Su protagonismo deja en un plano oculto a las mujeres, ya que las españolas relacionadas con la División Azul no fueron prisioneras. Pero la literatura se encargó, especialmente en el ámbito de la ficción, de otorgar a las mujeres la atención que no recibieron en los testimonios. Ya hemos explicado la cercanía temática entre El desconocido y El mensaje, con dos reacciones, en un principio, diferentes ante la ausencia del marido. Flora vive con Augusto porque da a Carlos por muerto mientras que Dominica, la esposa de Antonio en la novela de 
Carmen Kurtz, permanece junto a su familia política. Pero cuando se anuncia el regreso de los cautivos, las dos adoptan la misma actitud: Dominica acepta volver junto a él y, como ha señalado Lucía Montejo Gurruchaga, "se plegará a la autoridad dominante, al sistema de valores patriarcal” (20 Io: I6I-I62), a pesar de que "ella no le amara” (Kurtz, i 986: I6 I). Flora, aunque le dirá a Germán que nunca "amé a Carlos”, sino que se había casado con él "porque era la gran oportunidad de mi vida” (1963: 26), aceptará, al igual que el personaje de Kurtz, las obligaciones maritales de la posible vuelta de Carlos: "deseo con todas mis fuerzas que su nombre sea uno de la lista [...] [y] si es así, a su llegada encontrará la esposa y el hogar que deseó” (i 963: 42). La historia de Flora es, en cierto modo, la de las familias que durante más de una década dedicaron esfuerzos para saber sobre el destino de sus familiares (Rodríguez Jiménez, 2008).

Carlos, como hemos anunciado, es al mismo tiempo el motivador de la obra, el gran ausente y su presencia recorre los diferentes diálogos. ${ }^{\text {Io }}$ Los miembros de la División Azul prisioneros en el Gulag fueron presentados como aquellos que "alcanzaron una prematura madurez emocionada que había de llevarles necesariamente a la expansión, a la conquista, como en los mejores tiempos de nuestra historia" (Gómez y Montejano, I 954: 26). En el Gulag, destaca Germán que Carlos se comportaba con una fortaleza especial que "no se mide allá por la fuerza física, sino por la del espíritu", lo que hacía que, al contrario del resto de presos, que "pensamos en matarnos alguna vez", él no lo hiciera y con "su fuerza nos arrastró a todos hacia la esperanza” (1963: 20). El heroísmo de Carlos, que según el Asturias le convertía en "el único hombre de verdad" (1963: 22) del Gulag, es una excepción dentro de este tipo de relatos, en los que los presos, en distintos momentos, desean o presienten su muerte. Así ocurre con el alférez Ocañas (Puente, 1954: 26) cuando es capturado y ordena a sus compañeros que disparen contra él o con Juan Negro Castro ante la visión de una mina en la que debía trabajar,


los!" o "Mi primer marido... Carlos" ( $1963: 25$, 35 y 45). 
donde era "imposible dominar aquella sensación de muerte inmediata que nos sobrecogió" (1959: 283).

La supervivencia les costó a los presos un agotamiento físico extremo debido a la escasez alimentaria, lo que los presos llamaban "semihambre", que "implica no matar del todo el hambre por arriba ni reducir la alimentación hasta cero por abajo" (Puente, 1954: 100) y el sometimiento a trabajos forzados. En uno de estos es donde precisamente muere Carlos, lo que muestra la cara más extrema del Gulag y que coincide con lo estudiado más arriba por Todorov:

Muchos le conocieron, varios estuvieron en su mismo campo, y dos de ellos en su mismo barracón. He hablado con los que le vieron por última vez... Le sacaban, esposado, entre un piquete de guardianes. Le mandaban a un batallón de trabajo... Duro, durísimo trabajo. Dicen que miraba a sus compañeros como si se despidiera de ellos... Quizá pensaba en usted o en esta casa... Fue la única vez que le vieron triste, profundamente triste. Era natural. Sabía que, difícilmente, su debilidad física le permitiría sobrevivir a ese castigo [...] Nunca volvieron a hablar de él (1963: 52).

Hasta aquí hemos visto dos características inherentes al relato de los prisioneros del Gulag, especialmente propias de lo escrito por los veteranos de la División Azul: el heroísmo y el martirio. Pero ninguno ha contado que su motivación para alistarse fuera otra diferente a la ideológica. Ya hemos indicado que en Carlos no observamos este aspecto de manera clara, como sí ocurría en los testimonios de los hombres más politizados. Eusebio Calavia se alistó para "destruir vuestro régimen maldito y ayudar al pueblo ruso a liberarse del yugo que le tenéis impuesto" (1956: 160), una distinción que también realizaba Ramón P. Eizaguirre, que no fue "a luchar contra el pueblo ruso [...] sino contra el comunismo" (I955: I48). De la misma opinión eran Oroquieta Arbiol, que se enroló "para combatir al comunismo y a devolver la visita que nos hicieron los voluntarios rusos en nuestra Guerra Civil" (1958: 67) y Palacios Cueto, que formó parte de la División para "luchar contra el comunismo" (1993: 34). En cambio, Carlos pierde todo su resplandor como héroe y, como explica Flora, se marcha a la División Azul para buscar la muerte que le llega en el Gulag, al contrario de quienes fueron hasta allí para combatir al comunismo soviético: 
Yo, y todos los años de incomprensión que había vivido a mi lado [le impidieron volver]. En aquellas horas de espera, revivió sin duda los desprecios, las palabras, el dolor de las heridas... Y al fin, renunció al regreso. Augusto tenía razón. Carlos iba buscando la muerte... y el campo era lo que más se parecía a ella. No era un cobarde, ni mucho menos un egoísta... Siguió allí para evitarme su presencia... para que yo consiguiera, lo que a sus ojos era mi liberación... (Pausa larga.) Creo que al fin empezamos a comprender los dos su mensaje (1963: 63).

\section{A MODO DE CONCLUSIÓN}

El mensaje, de Jaime Salom, trata el tema del Gulag desde una perspectiva distinta a la que lo hicieron los testimonios publicados entre 1954 y i96o. Para ello, utiliza tres subtemas que encajan dentro del contexto español del Gulag: narra las relaciones entre los antiguos combatientes de la División Azul y los miembros del exilio republicano dentro de las rejas soviéticas. Allí, con reservas, tuvieron que luchar por el bien común de sobrevivir para, en un futuro cercano, recuperar la libertad. Esto lo hace en base a la complacencia de los vencedores de la Guerra Civil hacia los vencidos, considerados en todo momento como los equivocados en el ideal que descubrieron en la URSS las malas artes estalinistas. Sitúa en escena a Flora como el personaje principal de quienes intervienen en la obra. Ella es la mujer que se quedó en casa mientras el hombre se marchaba al frente del Este y que, tras creer que su marido había muerto, se enamora de otro hombre. Pero, al igual que retrataría dos años después Carmen Kurtz en su novela, ella está dispuesta a regresar a su matrimonio aunque este había muerto con el paso del tiempo. Vemos así cómo el paso del divisionario por el Gulag tuvo también consecuencias para la mujer, a pesar de no haber sido presa del mismo. Y presenta a Carlos como un héroe capaz de sufrir los males del Gulag, un mártir que da su vida en casa del enemigo ideológico y, sobre todo, como a un hombre con preocupaciones terrenales, lo que minimiza los efectos del heroísmo y el martirio. En este aspecto, el personaje de Carlos se aleja de los testimonios del Gulag, especialmente de los escritos por los divisionarios, quienes dieron inagotables pruebas de su oposición y altanería a los soviéticos. 
Esta obra de teatro puede ser incluida, como proponíamos en nuestra hipótesis, dentro de la literatura española del Gulag. Se trata de un caso especial dentro de un corpus dominado por los testimonios de los presos y que destina un espacio menor a las obras de ficción. Entre ellas, El mensaje se encuentra ligado a El desconocido al observar cómo las mujeres se adaptaron a las situaciones del cautiverio. Pero también entronca con la literatura testimonial del campo a través de las experiencias relatadas por Germán y el recuerdo constante de Carlos. Y, más allá de la coincidencia temática, sirve para recuperar la memoria de los españoles que sufrieron la penalidad del Gulag, un acontecimiento poco recordado en nuestros días pero que afectó a varias centenas de compatriotas cerca de setenta años atrás.

\section{BiBLIOGRAFÍA}

Aguirre, José Fernando (1959), “El mensaje, en el Alexis”, Hoja del lunes [ed. de Barcelona], i6- I 2I959, p. 2 I

A pplebaum, Anne (2014), Gulag: historia de los campos de concentración soviéticos, traducción de Magdalena Chocano, Barcelona: Debate.

Arasa, Daniel (2005), Los españoles de Stalin, Barcelona: Belacqua.

Calavia Bellosino, Eusebio y Francisco Álvarez Cosmen (1956), Enterrados en Rusia, Madrid: Editorial Saso.

Camps, Joaquín de (1953), "Prólogo del traductor", en Marqués de Custine, Rusia, ayer como boy, Barcelona: Destino, pp. 7-1 8.

Ciech anowski, Jan Stanislaw (2005), "Los campos de concentración en Europa. Algunas consideraciones sobre su definición, tipología y estudios comparados", Ayer, 57, pp. 5 I-79.

Conde Guerri, María José (2005), "Estudio introductorio", en Jaime Salom, Desde el escenario: reflexiones y recuerdos, Madrid: Fundación Autor, pp. 17-38.

Custine, Marqués de (1953), Rusia, ayer como boy, traducción de Joaquín de Camps, Barcelona: Destino.

Eizaguirre, Ramón P. (i 955), En el abismo rojo: Memorias de un español, once años prisionero en la URSS, Madrid: Reyma.

Farreras, Martí (1959), "El mensaje”, Destino, i 165, 5-1 2-1959, p. 45.

García Sánchez, César y Gerardo Oroquieta Arbiol (1958), De Leningrado a Odesa, Barcelona: AHR.

Genette, Gérard (1989), Palimpsestos: la literatura en segundo grado, traducción de Celia Fernández Prieto, Madrid: Taurus.

Gómez, José Luis y F. Montejano (1954), Los bravos del "Semíramis": reportaje en torno a los repatriados de la "División Azul", Pamplona: Editorial Gómez.

Guzmán Mora, Jesús (20I6), "Presos en Rusia: la memoria española del Gulag durante el franquismo (1954-1975)", Quaderns de filologia. Estudis literaris, 2 I, pp. Iо I-I I8. DOI: https: //doi.org/10.7203/qdfed.2 1.9337.

IbÂÑez Hernández, Rafael (1996), "Españoles en las trincheras: la División Azul”, en Stanley G. Payne y Delia Contreras (dirs.), España y la Segunda Guerra Mundial, Madrid: Editorial Complutense, pp. 55-88.

IORDACHe, Luiza (2014), En el Gulag: españoles republicanos en los campos de concentración de Stalin, Barcelona: RBA. 
IORDACHE, Luiza (2OI 5), "Los repatriados españoles de la URSS en el marco de la Guerra Fría (I954I960)", en Enrique Bengochea Tirado, Elena Monzón Pertejo y David G. Pérez Sarmiento (coords.), Relaciones en conflicto. Nuevas perspectivas sobre relaciones internacionales desde la historia, Valencia: Universitat de València, Asociación de Historia Contemporánea, pp. IO7-III.

IORDACHE, Luiza y Casilda GüELl (2OI 3), "Memoria del Gulag: el exilio y la emigración española en la URSS y la represión estalinista”, Historia contemporánea, 46, pp. 247-278. (Consultado online: http://www.ehu.eus/ojs/index.php/HC/article/view/I 278I/I I 56I [I4/o6/2018])

Izquierdo Gómez, Jesús (1993), Obra teatral de Jaime Salom, Granada: Servicio de Publicaciones de la Universidad de Granada.

JawOrSka, Krystyna Roza (20I4), "La letteratura tra spostamenti di confine e scollamenti temporali. Il caso della memorialistica polacca sui Gulag”, en Gianluca Coci, Mariagrazia Margarito y Massimo Maurizio (coords.), Confini in movimento: studi di letterature, culture e lingue moderne, Roma: Bonanno, pp. 53-72.

Kurtz, Carmen (1986), El desconocido, Barcelona: Planeta.

LÁzaro Ros, Amando (1952), Dios es corazón, Madrid: Rollán.

LuCA De Tena, Torcuato (1 993), Embajador en el infierno: memorias del Capitán Palacios. Once años de cautiverio en Rusia, Barcelona: Planeta.

Martínez Tomás, A. (I959), "Alexis - Estreno de la comedia El mensaje, original de Jaime Salom”, La Vanguardia Española, I 5-I 2-I 959, p. 90.

Montejo Gurruchaga, Lucía (2006), "La narrativa de Carmen Kurtz: compromiso y denuncia de la condición social de la mujer española de posguerra”, Arbor: ciencia, pensamiento y cultura, 719, pp. 407-415. DOI: https://doi.org/10.3989/arbor.2006.i719.40 .

Montejo Gurruchaga, Lucía (2010), Discurso de autora: género y censura en la narrativa española de posguerra, Madrid: Universidad Nacional de Educación a Distancia.

Moreno Juliá, Xavier (2005), La División Azul: sangre española en Rusia, 1941-1945, Barcelona: Crítica.

Negro Castro, Juan (1959), Españoles en la U.R.S.S., [Madrid]: Escelicer.

Preston, Paul (2005), "Prólogo", en Jaime Salom, Desde el escenario: reflexiones y recuerdos, Madrid: Fundación Autor, pp. 13-16.

Puente, Moisés (1954), Yo, muerto en Rusia (Memorias del Alférez Ocañas), Madrid: Ediciones del Movimiento.

Rodríguez Jiménez, José Luis (2007), De héroes e indeseables: la División Azul, Madrid: Espasa.

Rodríguez Jiménez, José Luis (2008), "El papel de las familias en las gestiones para la liberación de los prisioneros de la División Española de Voluntarios en la URSS”, Historia del presente, i I, pp. I4I-I64. (Consultado online: http://historiadelpresente.es/sites/default/files/revista/ articulos/ I I/ I r.gjoseluisrodriguezjimenezelpapeldelasfamiliasenlasgestionespara laliberaciondelosprisionerosdeladivis.pdf (Consultado el 5-4-20 1 8).

Rodríguez Puértolas, Julio (2008), Historia de la literatura fascista española, 2 vols. Madrid: Akal. SAlOM, Jaime (1963), El mensaje, Madrid: Escelier.

Salom, Jaime (2005), Desde el escenario: reflexiones y recuerdos, Madrid: Fundación Autor.

SÁNCHEZ ZAPATERO, Javier (2OIO), Escribir el horror: literatura y campos de concentración, Barcelona: Montesinos.

SÁnchez Zapatero, Javier (20I4), "Escritores, policías y atracadores", en Tomás Salvador, Los atracadores, ed. y prólogo de Javier Sánchez Zapatero, Madrid: Salto de página, pp. 5-i6.

Stark, Meinhard (1996), "Deutsche Frauen im Gulag”, en Robert Streibel y Hans Schafranek (eds.), Strategie des Überlebens. Häftlingsgesellschaften in KZ und Gulag, Viena: Picus Verlag, pp. $168-205$

Serrano, Secundino (20 I I), Españoles en el Gulag: republicanos bajo el estalinismo, Barcelona: Península.

Sin firma (1955), "Estreno de El mensaje en Bilbao", La Vanguardia Española, 26-5-1955, p. 22. 
Todorov, Tzvetan (2002), Memoria del mal, tentación del bien: indagación sobre el siglo XX, traducción de Manuel Serrat Crespo, Barcelona: Península.

Torres, Francisco (2018), Cautivos en Rusia: los últimos combatientes de la División Azul, Madrid: Actas.

Torres Nebrera, Gregorio (2004), Historia y antología del teatro español de posguerra (1940-1975). Vol. IV: 1956-1960, Madrid: Fundamentos.

Zatlin-Boring, Phyllis (1982), Jaime Salom, Boston: Twayne Publishers.

recibido: abril de 2018 aceptado: julio de 2018 
